
\title{
3 Research Square \\ Vital Signs of Severe COVID-19 Patients During Inter-Hospital Helicopter Transfer
}

Cornelis Slagt ( $\nabla$ cor.slagt@radboudumc.nl )

Radboud University Medical Centre

\section{Eduard Johannes Spoelder}

Radboud University Medical Centre

\section{Marijn Cornelia Theresia Tacken}

Radboud University Medical Centre

\section{Maartje Frijlink}

Radboud University Medical Centre

\section{Sjoerd Servaas}

Radboud University Medical Centre

\section{Guus Leijte}

Radboud University Medical Centre

Lucas Theodorus van Eijk

Radboud University Medical Centre

Geert Jan van Geffen

Radboud University Medical Centre

\section{Research Article}

Keywords: critical care, COVID-19, noninvasive hemodynamic monitoring, electrical cardiometry, vital signs, cardiac output. Helicopter Emergency Medical Service (HEMS), interhospital helicopter transfer

Posted Date: January 24th, 2022

DOl: https://doi.org/10.21203/rs.3.rs-1203192/v3

License: (9) This work is licensed under a Creative Commons Attribution 4.0 International License.

Read Full License 


\section{Abstract}

Background: During the COVID-19 pandemic in The Netherlands, critically ill ventilated COVID-19 patients were transferred not only between hospitals by ambulance but also by the Helicopter Emergency Medical Service (HEMS). To date, little is known about the impact of helicopter transport on critically ill patients and COVID-19 patients in particular. This study was conducted to explore the impact of inter-hospital helicopter transfer on vital signs of mechanically ventilated severe COVID-19 intensive care patients, with special focus on take-off, midflight, and landing.

Methods: All ventilated critically ill COVID-19 patients who were transported between April 2020 and June 2021 by the Dutch 'Lifeliner 5' HEMS team and who were fully monitored, including noninvasive cardiac output, were included in this study. Three 10-minute timeframes (take-off, midflight and landing) were defined for analysis. Continuous data on the vital parameters heart rate, peripheral oxygen saturation, arterial blood pressure, end-tidal $\mathrm{CO}_{2}$ and noninvasive cardiac output using electrical cardiometry were collected and stored at 1-minute intervals. Data were analydzed for differences over time within the timeframes using 1-way analysis of variance. Significant differences were checked for clinical relevance.

Results: Ninety-eight patients were included in the analysis. During take-off, an increase was noticed in cardiac output (from 6.7 to $8.1 \mathrm{Lmin}^{-1} ; \mathrm{P}<0.0001$ ), which was determined by a decrease in systemic vascular resistance (from 1068 to 750 dyne $\cdot \mathrm{s} \cdot \mathrm{cm}^{-5}, \mathrm{P}<0.0001$ ) accompanied by an increase in stroke volume (from 92.0 to $110.2 \mathrm{ml}, \mathrm{P}<0.0001$ ). Other parameters were unchanged during take-off and midflight. During landing, cardiac output and stroke volume slightly decreased (from 7.9 to $7.1 \mathrm{Lmin}^{-1}$, $\mathrm{P}<0.0001$ and from 108.3 to $100.6 \mathrm{ml}, \mathrm{P}<0.0001$, respectively), and total systemic vascular resistance increased $(P<0.0001)$. Though statistically significant, the found changes were small and not clinically relevant to the medical status of the patients as judged by the attending physicians.

Conclusions: Interhospital helicopter transfer of ventilated intensive care patients with COVID-19 can be performed safely and does not result in clinically relevant changes in vital signs.

This study was assessed by the medical ethical committee Arnhem-Nijmegen, the Netherlands (identifier 2021-7313). The committee waived the need for informed consent. The study was registered at www.trialregister.nl (identifier NL9307).

\section{Background}

During peak coronavirus-2 (SARS-CoV-2) spread, health care systems around the world were overwhelmed, with patients suffering from respiratory failure, many of whom needed hospitalization for ventilatory support. Distinctive of the COVID-19 outbreak was the emergence of regional hotspots, with large numbers of patients requiring intensive care (IC) due to acute respiratory failure [1]. Severe COVID19 presents with progressive dyspnea and often with hypoxemia [2,3]. COVID-19 lung disease resembles 
ARDS and may rapidly progress to multiorgan failure [4]. Approximately $5 \%$ of severe COVID-19 patients require intubation and ventilation [5].

Before the COVID-19 pandemic, inter-hospital ICU transfer was performed with mobile intensive care units (MICUs); specialized ambulances equipped as an ICU. When locally an IC bed capacity problem arose, it was resolved by transferring patients regionally. Unfortunately, during the pandemic, the regional ICU capacity was insufficient at several hotspots in the Netherlands. Anticipating an increase in long-distance transfers, the team of Helicopter Emergency Medical Service (HEMS) Lifeliner 3 of the Radboud University Medical Center received permission from the Ministry of Health, Wellbeing and Sports to organize and operate the first ICU-equipped helicopter (Lifeliner 5) for transferring and redistributing critically ill COVID19 patients in the Netherlands. This operation was initiated in cooperation with the Medical Air Assistance subdivision of the Royal Dutch Touring Club. It has been described in the literature that helicopter transport of ICU patients is feasible and safe for patients and personnel [6].

However, it has been acknowledged that (long distance) transfers of ICU patients (inter-, intra- and prehospital) bear the risk of complications. Most of the (severe) complications are thought to be reflected by changes in vital signs [7-10]. With regard to helicopter transportation, specific concerns have been raised with regard to the effects of barometric pressure variations and acceleration/deceleration during take-off and landing [11]. Therefore, the goal of this study was to analyze the impact of interhospital helicopter transfer on vital signs of mechanically ventilated severe COVID-19 ICU patients with special attention to differences between take-off, mid-flight, and landing.

\section{Methods}

This prospective observational study was performed during the COVID-19 outbursts in the Netherlands. In this prospective observational study, mechanically ventilated COVID-19 ICU patients who were monitored, including noninvasive cardiac output (CO), were included from the end of the first outburst in April 2020 throughout the end of the second outburst in June 2021. This study was assessed by the medical ethical committee Arnhem-Nijmegen, the Netherlands (identifier 2021-7313). This study will be carried out in accordance with the applicable legislation and policy rules. The committee waived the need for informed consent. The study was registered at www.trialregister.nl (identifier NL9307).

\section{Data collection}

Before monitoring started, monitoring devices were synchronized with the helicopter set-time and date. Three 10 minute timeframes were defined for analysis. The first timeframe started with the actual takeoff. The second timeframe represented midflight, and the third timeframe ended with the landing (touching of the ground). Data were extracted from the documented flight reports in the Operational Registration and Crew Administration data system. Continuous vital parameter data, including heart rate $(\mathrm{HR})$, peripheral oxygen saturation $\left(\mathrm{SpO}_{2}\right)$, arterial blood pressure (IAP), systolic, diastolic and mean 
arterial blood pressure (SBP, DBP and MAP), and end tidal $\mathrm{CO}_{2}\left(\right.$ et- $\left.-\mathrm{CO}_{2}\right)$, were collected for every patient during helicopter transfer using a Corpuls 3 monitor (Corpuls ${ }^{\circledR}$ Benelux, Hellevoetsluis, The Netherlands).

\section{Noninvasive cardiac output measurement by electrical cardiometry}

As cardiac involvement of SARS-CoV-2 was suggested during the first COVID-19 outburst [12], we expanded our standard monitoring in the second outburst with noninvasive cardiac output measurement using electrical cardiometry $(\mathrm{EC})$. Doctors and nurses were trained in the use of the noninvasive $\mathrm{CO}$ monitoring device (ICON ${ }^{\circledR}$ monitor, Osypka Medical GmbH, Germany). The EC device was connected to the patient according to the manufacturer's instructions using 4 skin sensors. These allowed continuous measurement of changes in thoracic electrical conductivity in response to a low amplitude, high frequency electrical current. Filtering techniques isolate changes in conductivity created by the circulatory system, which is mainly determined by blood in the aorta and its change in conductivity when subjected to pulsatile blood flow before and after aortic valve opening. This is used to derive the peak aortic acceleration (ACC) and left ventricle ejection time (LVET). Stroke volume (SV) is calculated using patient characteristics (gender, age, length, body weight), ACC and LVET [13,14]. Further details of the device are described by Bernstein and colleagues [13,15]. As central venous pressure was not recorded, total systemic vascular resistance (TSVR) was calculated using the formula MAP/CO*80 (dyne $\cdot \mathrm{s} \cdot \mathrm{cm}^{-5}$ ) as described in the literature [16]. Vital signs, including noninvasive $\mathrm{CO}$ data, were recorded at 1-minute intervals.

\section{Adverse events}

Major adverse events during inter-hospital transfer were defined as cardiac or respiratory arrest, pneumothorax or seizure. Minor adverse events were defined as new undesirable changes in vital signs. Standard target values of hemodynamics for patients in the ICU are well defined; however, cut-off values for vital signs that are considered to be causing harm are less well defined. In this study, cut-off values were defined according to the available literature, taking into account that this study included critically ill patients. We defined the following thresholds: MAP $<60$ and $<65$ or $>120 \mathrm{mmHg} ; \mathrm{SpO}_{2}<88$ and $90 \%$; et$\mathrm{CO}_{2}<25$ or $>55 \mathrm{mmHg} ; \mathrm{HR}<50$ and $>100 \mathrm{bpm}$ requiring treatment [17-21].

\section{Statistical analysis}

For the analyses and comparison of vital parameters, the aforementioned 10-minute window of patient data at take-off, mid-flight and landing was used. The resolution for vital sign data was set at 1 minute. In the case of missing data, only timeframes with $\geq 6$ data points were eligible for analysis. Missing data were interpolated with the mean of previous and next data points or extrapolated with the last observation carried forward. Data were assessed for normal distribution using the Kolmogorov-Smirnov test and presented accordingly (normally distributed data with mean \pm standard deviation and not normally distributed data with median [interquartile range]). For every vital parameter, differences over time within the group were analysed using 1-way analysis of variance (ANOVA) and Dunnett's multiple 
comparison test for post hoc analysis. Not normally distributed data were $\log 10(\mathrm{x})$ transformed before analysis with 1-way ANOVA. A P-value $<0.05$ was considered statistically significant. All statistically significant differences were checked for clinical relevance [16-20]. Data were analysed using the appropriate tests in GraphPad Prism version 5.03 (GraphPad software, San Diego, USA).

\section{Results}

\section{Patient characteristics}

Ninety-eight patients were included in this analysis. Patient characteristics are shown in table 1.

Most patients were deeply sedated, receiving one or two (49\%) sedatives (midazolam and propofol) opioids $93 \%$ and rocuronium $46 \%$. Bolus medication (midazolam, opioid, propofol, ketamine, norepinephrine or phenylephrine) was given in 70 patients to facilitate safe transportation and reduce oxygen consumption and carbon dioxide production. Eighty-four patients received continuous norepinephrine to support hemodynamics.

Data

All continuous parameters were recorded at a 1-minute interval during all timeframes. Technical monitoring problems led to the loss of 281 data points (1.6\% of total). For CO, SV and TSVR, a total of 522 timeframes were available for analysis $(59.1 \%$ of total).

No profound changes in vital parameters during take-off, midflight and landing

Overall, no profoundly clinically relevant changes were observed in vital signs during inter-hospital helicopter transfer of ventilated COVID-19 patients (Figure 1, Figure 2, Suppl. Figure 3, Table 2). Although there were several statistically significant changes within the timeframes (Table 2), these were not deemed clinically relevant, as most values were within normal ranges. [17-21].

Figure 1. Vital signs during take-off, midflight and landing.

Data are expressed as median and interquartile range. $\mathrm{Bpm}=$ beats per minute. ${ }^{*} \mathrm{P}<0.05$ measured using Dunnett's multiple comparison test. Consecutive measurements in each timeframe are compared to the first measurement in that timeframe. Figure 2. Noninvasive cardiac output data during take-off, midflight and landing

Data are expressed as median and interquartile range. $\mathrm{L} / \mathrm{min}=$ liter per minute; $\mathrm{mL}=$ milliliter. $* \mathrm{P}<0.05$ measured using Dunnett's multiple comparison test. Consecutive measurements in each timeframe are compared to the first measurement in that timeframe.

Supplement

Figure 3. Systolic and diastolic blood pressure during take-off, midflight and landing 
Data are expressed as median and interquartile range. ${ }^{*} \mathrm{P}<0.05$ measured using Dunnett's multiple comparison test. Consecutive measurements in each timeframe are compared to the first measurement in that timeframe.

During take-off, there were no significant changes in key vital signs, such as $\mathrm{HR}, \mathrm{CO}_{2}, \mathrm{SpO}_{2}$ and IAP. As expected, mid-flight was the most stable part with respect to vital signs; only for $\mathrm{SpO}_{2}$ was a difference over time seen. During take-off, an increase in stroke volume (from 92.0 to $110.2 \mathrm{ml}, \mathrm{P}<0.0001$ ) was found. This led to an increase in cardiac output (from 6.7 to $8.1 \mathrm{Lmin}^{-1} ; \mathrm{P}<0.0001$ ). With minimal changes in MAP, this led to a decrease in systemic vascular resistance (from 1068 to 750 dyne $\cdot \mathrm{s} \cdot \mathrm{cm}^{-5}, P<0.0001$. In the last 1 minute, MAP and et- $\mathrm{CO}_{2}$ show significant changes just before landing.

\section{Adverse events}

No major adverse events took place during the transfers. Minor adverse events are depicted in Table 3. The most frequently observed adverse event was a new MAP $<65 \mathrm{mmHg}$, and only 2 events lasted longer than $5 \mathrm{~min}$. None of the MAP< $60 \mathrm{mmHg}$ events lasted longer than $5 \mathrm{~min}$.

\section{Discussion}

The current observational study showed that inter-hospital helicopter transport of mechanically ventilated COVID-19 patients can be performed safely. No clinically relevant changes in regular heart rate, oxygen saturation, blood pressure or et- $\mathrm{CO}_{2}$ were observed during take-off, mid-flight or landing.

Several studies have described the organization and quality of intensive care transport [2224]; however, most data are obtained from road transfers using MICUs, and data about COVID-19 transports are limited $[20,25,26]$. In the early days, Waddell and colleagues described the impact of ambulance transport on the vital signs of critically ill patients [27]. They documented considerable variation in hemodynamic responses to transport between patients. Increased mortality was found in individuals who developed hypertension or hypotension compared to patients with no change or delayed hypotension. Other authors did not find increased mortality after interhospital transfer by ambulance or MICU [10,28].

Malagon et al. investigated noninvasive cardiac output during fixed wing air ambulance repatriation using suprasternal Doppler [29]. Six medical crew members and 7 patients were assessed on the ground, during take-off, in the air and during decent. They found a statistically significant increase in $\mathrm{CO}$ and SV during take-off. A possible explanation was the combination of G-forces and the occurrence of mild hypoxia releasing NO mediators. However, similar to our findings, their changes were without clinical relevance. Our patients were on mechanical ventilation and thus received supplemental oxygen. The cruising altitude of our IC-helicopter was between 800-1200 feet. Taken together, relative hypoxia was not a contributing factor during our transport. Gravitational forces are limited during medical helicopter transport. During take-off and 
landing, acceleration/deceleration occurs in a 1-2 minute window after take-off and before landing. During the entire flight, vibration of the helicopter could induce pooling of venous blood, thereby changing cardiac preload and influencing SV and CO. Probably more important, during the first minute of actual lift off, the patient is positioned in a head-up position; hereafter, the patient is positioned in a slight headdown position during the entire flight. This position increases venous return and might be responsible for the observed increase in SV and CO. The observed increase in SV and CO led to an increase in oxygen delivery which is anything but an adverse event $[17,21]$.

Although noninvasive $\mathrm{CO}$ measurements have been performed before in the prehospital HEMS setting [30,31], limited data are available on CO measurements during IC-helicopter transports, let alone COVID19 transfers [30,31]. Our study is the first to attempt CO measurements during interhospital helicopter transfer in ventilated IC patients with COVID-19. In all 98 patients, noninvasive CO measurements were performed. However, $59.6 \%$ of the timeframes were available for analysis due to missing data. As ICON measures changes in electrical conductivity within the thorax in response to a low amplitude, highfrequency electrical current, the signal could plausibly be influenced by vibrations or movement generated during flight $[14,15,31]$. In previous work, ICON hemodynamic monitoring in the prehospital emergency medical setting showed that $23.6 \%$ of all measurements were lost due to interference with the signal. In that study, five out of 50 patients were transferred by helicopter, and all had good measurements [31].

With only $1.65 \%$ missing data of the conventional vital sign parameters, a robust data set was created to evaluate the impact of interhospital helicopter transport. Although there is no consensus for strict target parameters, Alhazzani et al. provided guidelines for the general management of critically ill adults suffering from COVID-19 [17]. They suggested an $\mathrm{SpO}_{2} \geq 90 \%$ in patients with acute hypoxemic respiratory failure. A target MAP of $60-65 \mathrm{mmHg}$ is suggested, often requiring vasopressor support due to the high ventilation pressures needed to optimize ventilation and to counteract deeply sedated patients $[3,17]$. In accordance, $84 \%$ of our patients needed vasopressor therapy to support the circulation. Extra sedation was given to optimize ventilation, reduce oxygen consumption, decrease carbon dioxide production and reduce the stresses of flight, which could have had an impact on the measured vital signs. No major adverse events occurred, and only limited minor adverse events were recorded in our study, in which we flew more than $15000 \mathrm{~km}$ with COVID-19 patients.

This study has some limitations. We conducted research in a relatively new patient population in a singlecentre study. Therefore, extrapolation of these results to other intensive care patients may be limited. The loss of $40.4 \%$ of the noninvasive hemodynamic data may be due to signal interference of the electrical cardiometry device by the helicopter.

\section{Conclusion}

Interhospital helicopter transport of ventilated intensive care COVID-19 patients can be performed safely. Although some significant changes in vital signs during take-off, mid-flight and landing were found, these 
seem not clinically relevant. Vital signs are merely within the normal ranges of vital signs seen during intensive care treatment.

\section{List Of Abbreviations}

$\begin{array}{ll}\text { ACC } & \text { aortic acceleration } \\ \text { CO } & \text { cardiac output } \\ \text { DBP } & \text { diastolic blood pressure } \\ \text { EC } & \text { electrical cardiometry } \\ \text { et-CO } & \text { end tidal } \mathrm{CO}_{2} \\ \text { HEMS } & \text { Helicopter Emergency Medical Service } \\ \text { HR } & \text { heartrate } \\ \text { IAP } & \text { arterial blood pressure } \\ \text { IC } & \text { intensive care } \\ \text { ICU } & \text { intensive care unit } \\ \text { LVET } & \text { left ventricle ejection time } \\ \text { MAP } & \text { mean arterial blood pressure } \\ \text { MICU } & \text { Mobile Intensive Care Units } \\ \text { SBP } & \text { systolic blood pressure } \\ \text { SpO } & \text { peripheral oxygen saturation } \\ \text { SV } & \text { stroke volume } \\ \text { TSVR } & \text { total systemic vascular resistance }\end{array}$

\section{Declarations}

Ethics approval and consent to participate 
This study was assessed by the medical ethical committee Arnhem-Nijmegen, the Netherlands (identifier 2021-7313) by Prof. Dr. P.N.R. Dekhuijzen, Chairman 18-02-2021. This study will be carried out in accordance with the applicable legislation and policy rules. The committee waived the need for informed consent.

Consent for publication

Not applicable

Availability of data and materials

The datasets used and/or analysed during the current study are available from the corresponding author on reasonable request.

Competing interests

The authors declare that they have no competing interests.

Funding

The authors thank Osypka Medical for providing the ICON® monitor. Osypka Medical provided no financial support and had no role in the data collection, analysis, and writing of the manuscript.

Author's contributions

CS participated in the literature search, study design, data collection and analysis, interpretation, writing and approval of the final version. ES participated in the study design, data collection, interpretation, writing and approval of the final version. SS participated in the study design, data analysis, interpretation, writing and approval of the final version, and MT participated in the data collection, interpretation, writing and approval of the final version. GL participated in the data collection, interpretation, writing and approval of the final version. MF participated in the data collection, interpretation, writing and approval of the final version. GJvG participated in the study design, data collection, interpretation, writing and approval of the final version, and LvE participated in the study design and analysis, interpretation, writing and approval of the final version.

Acknowledgements

Not Applicable

\section{References}

1. Wu Z, McGoogan JM. Characteristics of and important lessons from the coronavirus disease 2019 (COVID-19) outbreak in China: summary of a report of 72,314 cases from the Chinese Center for Disease Control and Prevention. JAMA 2020;323:1239-42. 
2. Zhou F, Yu T, Du R, Fan G, Liu Y, Liu Z, et al. Clinical course and risk factors for mortality of adult inpatients with COVID-19 in Wuhan, China: a retrospective cohort study. Lancet 2020;395:1054-62.

3. Manthous CA, Hall JB, Kushner R, Schmidt GA, Russo G, Wood LD. The effect of mechanical ventilation on oxygen consumption in critically ill patients. Am J Respir Crit Care Med 1995;151:210214.

4. Huang C, Wang Y, Li X, Ren L, Zhao J, Hu Y, et al. Clinical 'features of patients infected with 2019 novel coronavirus in Wuhan, China. Lancet 2020; 395: 497-506.

5. Berlin DA, Gulick RM , Martinez FJ. Severe Covid-19. N Engl J Med. 2020;383:2451-2460.

6. Spoelder EJ, Tacken MCT, van Geffen GJ, Slagt C. Helicopter transport of critical care COVID-19 patients in the Netherlands: protection against COVID-19 exposure-a challenge to critical care retrieval personnel in a novel operation. Scand J Trauma Resusc Emerg Med. 2021;29:41.

7. Waydhas C. Intrahospital transport of critically ill patients Crit Care. 1999;3:R83-9.

8. Beckmann U, Gillies DM, Berenholtz SM, Wu AW, Pronovost P. Incidents relating to the intra-hospital transfer of critically ill patients. An analysis of the reports submitted to the Australian Incident Monitoring Study in Intensive Care. Intensive Care Med. 2004;30:1579-85.

9. Flabouris A, Runciman W B, Levings B. Incidents during out-of-hospital patient transportation. Anaesth Intensive Care. 2006;34:228-36.

10. Duke GJ, Green JV Outcome of critically ill patients undergoing inter-hospital transfer. Med J Aust. 2001;174:122-125.

11. Maissan IM, Verbaan LA, van den Berg M, Houmes RJ, Stolker RJ, den Hartog D. Helicopter Transportation Increases Intracranial Pressure: a Proof-of-Principle Study. Air Med J. 2018;37:249252..

12. Guo T, Fan $Y$, Chen $M$, Wu $X$, Zhang $L$, He T, et al. Cardiovascular implications of fatal outcomes of patients with coronavirus disease 2019 (COVID-19). JAMA Cardiol. 2020;5:811-8.

13. Bernstein DP, Osypka MJ (2003) Apparatus and method for determining an approximation of the stroke volume and the cardiac output of the heart. US Patent 6,511,438. https://patents.google.com/patent/US6511438B2/en

14. Bernstein DP, Lemmens HJ (2005) Stroke volume equation for impedance cardiography. Med Biol Eng Comput. 43:443-50.

15. https://www.osypkamed.com/electrical-cardiometry-technology-ec (assessed on 15-12-2021).

16. De Backer D, Marx G, Tan A, Junker C, Van Nuffelen M, Hüter L, et al. Arterial pressure-based cardiac output monitoring: a multicenter validation of the third-generation software in septic patients. Intensive Care Med. 2011;37:233-40.

17. Alhazzani W, Møller MH, Arabi YM, Loeb M, Gong MN, Fan E, et al. Surviving Sepsis Campaign: guidelines on the management of critically ill adults with coronavirus disease 2019 (COVID-19). Intensive Care Med. 2020;46:854-87.

18. Slama M, Modeliar SS. Hypertension in the intensive care unit. Curr Opin Cardiol.. 2006;21:279-87. 
19. Seymour CW, Kahn JM, Schwab CW, Fuchs BD. Adverse events during rotary-wing transport of mechanically ventilated patients: a retrospective cohort study. Crit Care. 2008;12:R71.

20. Frakes MA, Richards JB, Cocchi MN, Cohen A, Cohen JE, Dargin J, et al. Critical Care Transport of Patients With COVID-19. J Intensive Care Med. 2021;36:704-710.

21. Muller JC, Kennard JW, Browne JS, Fecher AM, Hayward TZ. Hemodynamic monitoring in the intensive care unit. Nutr Clin Pract. 2012;27:340-51.

22. Wallace PG, Ridley SA. ABC of intensive care. Transport of critically ill patients. BMJ. 1999;319:36871.

23. Droogh JM, Smit M, Absalom AR, Ligtenberg JJ, Zijlstra JG. Transferring the critically ill patient: are we there yet? Crit Care. 2015;19:62.

24. The Faculty of Intensive care medicine. Guidance on: the transfer of the critically ill adult. https://www.gmccmt.org.uk/wp-content/uploads/2019/10/ICS-2019-Transfer-Guidance.pdf (assessed on 15-12-2021)

25. Hilbert-Carius P, Braun J, Abu-Zidan F, Adler J, Knapp J, Dandrifosse D, et al. Pre-hospital care \& interfacility transport of 385 COVID-19 emergency patients: an air ambulance perspective. Scand J Trauma Resusc Emerg Med. 2020;28:94.

26. Bredmose PP, Diczbalis M, Butterfield E, Habig K, Pearce A, Osbakk SA, et al. Decision support tool and suggestions for the development of guidelines for the helicopter transport of patients with COVID-19. Scand J Trauma Resusc Emerg Med. 2020;28:43.

27. Waddell G, Scott PDR, Lees NW, Ledingham MCA. Effects of Ambulance Transport in Critically III Patients. Br Med J. 1975;1:386-389.

28. Strauch U, Bergmans DCJJ, Winkens B, Roekaerts PMHJ. Short-term outcomes and mortality after interhospital intensive care transportation: an observational prospective cohort study of 368 consecutive transports with a mobile intensive care unit. BMJ Open 2015;5:e006801.

29. Malagon I, Grounds R M, Bennett E D. Changes in cardiac output during air ambulance repatriation. Intensive Care Med. 1996;22:1396-9.

30. Knobloch K, Hubrich V, Rohmann P, Lupkemann M, Gerich T, Krettek C, et al. Feasibility of preclinical cardiac output and systemic vascular resistance in HEMS in thoracic pain-the ultrasonic cardiac output monitor. Air Med J. 2006;25:270-5.

31. Slagt C, Servaas S, Ketelaars R, van Geffen GJ, Tacken MCT, Verrips CA, et al. Non-invasive electrical cardiometry cardiac output monitoring during prehospital helicopter emergency medical care: a feasibility study. J Clin Monit Comput. 2021 Jan 23. doi: 10.1007/s10877-021-00657-5. Online ahead of print.

\section{Tables}

Due to technical limitations, table 1 is only available as a download in the Supplemental Files section. 


\begin{tabular}{|llll|}
\hline \multicolumn{4}{|l|}{ 1way ANOVA on log transformed data } \\
\hline & Take-off & Midflight & Landing \\
\hline $\mathrm{SpO}_{2}$ & 0.58 & $<0.0001$ & 0.84 \\
\hline $\mathrm{HR}$ & 0.62 & 0.52 & 0.57 \\
\hline $\mathrm{SVR}$ & $<0.0001$ & 0.53 & $<0.0001$ \\
\hline $\mathrm{CO}$ & $<0.0001$ & 0.32 & $<0.0001$ \\
\hline $\mathrm{SV}$ & $<0.0001$ & 0.40 & $<0.0001$ \\
\hline $\mathrm{MAP}$ & 0.50 & 0.77 & $<0.0001$ \\
\hline $\mathrm{SBP}$ & 0.90 & 0.96 & $<0.0001$ \\
\hline $\mathrm{DBP}$ & 0.58 & 0.27 & 0.25 \\
\hline $\mathrm{CO}_{2}$ & 0.56 & 0.46 & $<0.0001$ \\
\hline
\end{tabular}

$\mathrm{SpO}_{2}=$ peripheral venous saturation; $\mathrm{HR}=$ heart rate; $\mathrm{SVR}=$ systemic vascular resistance; $\mathrm{CO}=$ cardiac output; $\mathrm{SV}$ = stroke volume; $\mathrm{MAP}=$ mean arterial pressure; $\mathrm{SBP}=$ systolic blood pressure; $\mathrm{DBP}$ $=$ diastolic blood pressure; $\mathrm{CO}_{2}=$ end tidal carbon dioxide. ${ }^{*} \mathrm{P}<0.05$ measured using 1-way ANOVA.

Table 3. Minor adverse events

\begin{tabular}{|lllll|}
\hline & Take-off & Midflight & Landing & Total \\
\hline $\mathrm{MAP}<65 \mathrm{mmHg}$ & 11 & 9 & 9 & 29 \\
$<60 \mathrm{mmHg}$ & 3 & 1 & 3 & 7 \\
$>120 \mathrm{mmHg}$ & 4 & 2 & - & 6 \\
\hline $\mathrm{SpO}_{2}<90 \%$ & 3 & - & 2 & 5 \\
$<88 \%$ & 1 & 1 & 2 & 4 \\
$\mathrm{Et}_{-}-\mathrm{CO}_{2}<25 \mathrm{mmHg}$ & - & 1 & - & 1 \\
$>55 \mathrm{mmHg}$ & 1 & 2 & 1 & 4 \\
\hline $\mathrm{HR}^{*}<50 \mathrm{bpm}$ & - & - & - & - \\
$>100 \mathrm{bpm}$ & - & - & - & - \\
\hline Total & 23 & 16 & 17 & 56 \\
\hline
\end{tabular}

$\mathrm{SpO}_{2}=$ peripheral venous saturation; $\mathrm{HR}^{\star}$ = heart rate requiring treatment; $\mathrm{MAP}$ = mean arterial pressure; et- $\mathrm{CO}_{2}=$ end tidal carbon dioxide 


\section{Figures}

\section{Figure 1}

Vital signs during take-off, midflight and landing.

\section{Figure 2}

Noninvasive cardiac output data during take-off, midflight and landing

Figure 3

Systolic and diastolic blood pressure during take-off, midflight and landing

\section{Supplementary Files}

This is a list of supplementary files associated with this preprint. Click to download.

- Table1.docx 